\title{
In vitro Study on the Dimensional Stability of Interocclusal Recording Materials
}

\author{
DIANA CERGHIZAN², KAMEL EARAR²*, MIHAELA MONICA SCUTARIU³, ALINA RAMONA DIMOFTE², GINA PAUNITA GRECU², \\ KINGA J ANOSI ${ }^{1}$ \\ 'University of Medicine and Pharmacy of Targu Mures, Faculty of Dental Medicine, 38 Gh. Marinescu Str., 540139, Tg. Mures, \\ Romania \\ 2Dunarea de Jos University of Galati, Faculty of Medicine and Pharmacy, Department of Dentistry, 47 Domneasca Str., 800008, \\ Galati, Romania \\ 3University of Medicine and Pharmacy Grigore T. Popa of Iasi, Faculty of Dental Medicine,16 Universitatii Str.,700115, Iasi, \\ Romania
}

\begin{abstract}
The teeth are found in the alveolar processes of both the upper and lower jaw and they form the two maxillary and mandibular dental arches, the various relations of which support the performance of the dental apparatus functions, one of the most important of which is mastication. These relations are also known as interocclusal relations, among which the moments in which the dento-dental contacts (occlusal relations) play an important role. Maximum intercuspation (MI) is the most frequent mandibulo-cranial functional position with dento-dental contact. The vast majority of functional food incision and mastication cycles end in MI. The highest number of dento-dental contacts, and the largest possible stability and surface of these contacts are also achieved in MI. Given the relative easiness of determination, recording and transfer of the MI position, it is used in many clinical situations to report the models of the two arches. The interocclusal recording materials used in our study were seven silicones, six of which with addition reaction, five with special destination for interocclusal relation determination and a putty-like silicone normally used for dental arch impression - Elite HD and one condensation silicone used for impressions. The reason for choosing the last two materials was the fact that some practitioners frequently use putty-like impression silicone to determine interocclusal relations. According to the findings of the measurements shown in table 1, further to the initial impression process, at the time T0, satisfactory results were obtained both for addition silicones and for condensation silicones, Registrado X-tra being the only recording material which exhibited major deviation from the standard dimension $(3 \mathrm{~mm})$. As for the Optosil condensation silicone, we noted a significant increase of the thickness of the material starting with the firsthour after impression and reaching considerable values on the $5^{\text {th }}$ day, which were $0.3 \mathrm{~mm}$ higher than the standard value. Rigid addition silicones have the lowest dimensional stability; putty-like silicones are frequently used to record interocclusal relations for fixed prosthetics, which is wrong since they grow rapidly and this impedes on the space between the treated tooth and the opposite tooth, the result being a high restoration, which may determine premature contacts. Except for Optosil, which exhibited a continuous increase, most materials may be used to mount models in the simulator after $24 \mathrm{~h}$.
\end{abstract}

Keywords: interocclusal relations, silicones, occlusal relations, morphological components, dental prosthetics

The dental apparatus seems to be the most complex apparatus of the human body, both in what concerns its morphological components, and in relation to the very different functionality of this apparatus [3]. The main bone structures of the dental apparatus are the two bones, the upper and lower jaws, the former fixed, immobile, and the latter mobile, capable to set various relations towards the former. These differentrelations existing between the lower and upper jaws are included in the complex notion of interocclusal relations [3]. The study of interocclusal relations is extremely important for dental prosthetics for several reasons: any prosthetic treatment should be initiated only after a thorough occlusal (morphological and functional) analysis has been conducted to detect any possible deviations from normal, functional, in order to prevent them; in the absence of this preprosthetic occlusal preparation, the prosthetic treatment will only perpetuate the abnormal situation and will immediately contribute to the unfavorable evolution, meaning that the dental apparatus structures and functions are damaged; any dental treatment and especially the prosthetic treatment change occlusal morphology; functional occlusal relations may also be impaired; prosthetic treatment reliability may be flawed especially since the functional occlusal requirements are not met, many of the prosthetic failures being caused by the lack of functional occlusal adaptation of the prosthetic parts (suffice itto mention the inexplicable decementations); only the knowledge and application of the notions of functional occlusal relations allow preventing the onset of symptoms, often remotely from the place where the prosthesis is placed; both the cause and solution of these symptoms are still unknown [3].

Occlusal relations should be viewed as dynamic relations, as they refer to the different positions of the lower jaw towards the upper jaw, and also to the displacements of the lower jaw, to its functional movements and to lower jaw kinematics. Many of these relations are influenced by occlusal morphology, i.e. those elements involved in occlusal functionality [3].

Interocclusal recording is the centric relation (CR) position transfer method which is the most frequently used in clinical practice. In fact, in addition to CR, any other mandibular-cranial diagnostic position with dento-dental contact (MI-maximum intercuspation, EEP-end-to-end in propulsion, EEL-end-to-end in right or left laterality), a position which we will subsequently refer to, may be

\footnotetext{
* email: erar_dr.kamel@yahoo.com
} 
translated in laboratory by means of interocclusal recordings [3].

\section{Recording principles}

Interocclusal recording is the impression of the occlusal surfaces (incisal edges) of both arches, found in the expected relation. Usually, the model is not cast in this impression, but other models of single-tooth impressions are placed here.

For a proper relation between the two models, their placing in the occlusion recording should be very accurate. This requirement also determines the conditions that an accurate interocclusal recording should meet: the recording should not exceed the clinical equator (the tip of the cusps).

The material used and found between the occlusal surfaces of the teeth of the two arches should not allow deformation during its relative positioning and model fastening in the occlusor or articulator. The use of elastic interocclusal recording materials (silicones or polyethers) is reserved to the case in which the position the recording refers to has sufficient dento-dental contacts, and these contacts are stable; practically, only the maximum intercuspation (MI) position meets these requirements. The other interocclusal recordings (CR, propulsion, laterality) should be done using rigid or semirigid materials [3] .

\section{Objectives}

Therefore, special attention should be paid to the stretching of the impression material over the oral surfaces of the side teeth on the lower jaw, in which, due to crown lingualization, the clinical equator is often placed very close to the occlusal surface [3].

On the vestibular surface, the recording should onlycover the tips of the cusps [3].

Both the material and the technique used for the recording of the interocclusal relations should reduce any intra-oral adjustment of the prosthesis. Nevertheless, the errors are often due to the biological characteristics of the stomatognathic system and to mistakes of the attending dentist. In order to prevent clinical errors, the procedure used for interocclusal relation recording and stabilization should be carried out with the utmost care and attention [2].

Interocclusal relation recording is an important step in oral rehabilitation. This relation is transferred to the articulator, so that the laboratory procedures carried out on moulds will correspond to the changes occurring in the patient's oral cavity [2].

The introduction of the various interocclusal recording relation materials has made dentists wonder about which of them were the best for clinical practice, for an accurate recording and for the transfer of existing occlusal relations, for patient diagnosis setting or for mould production, in order to obtain satisfactory prostheses [1].

In the era of an unprecedented development of the dental medicine w orld, the different interocclusal relation recording materials are introduced under various brand names. This is the reason why the use of these materials is confusing, as there are no in vitro or in vivo studies describing the properties of the materials and making recommendations concerning their use [1]. Interocclusal recording using different methods and materials will play a positive role in insuring the occlusion expected from prosthetic devices.

In 1756, Phillip Pfaff was the first to record interocclusal relations by means of natural waxes. Both the materials and the techniques used to record interocclusal relations have evolved since. These materials are practically impression materials that were modified to have better handling characteristics. We may include here plaster, dental wax, ZOE paste, acrylic resin, hydrocolloid, polyether and polyvinyl siloxane impressions [1].

Dental wax and ZOE paste have been used from the beginning of the dental medicine era as interocclusal relation recording materials, due to their easy handling and cost effectiveness. They were classified as basic materials for the development of new interocclusal relation recording materials and methods [1].

The diagnosis setting and treatment of a patient needing prosthetic rehabilitation require from the clinician both study models (documentation), and work models, as well as their mounting in an articulator. In order to do that, the interocclusal relations should be recorded and the data should be transferred to the articulator. Interocclusal recording renders the precise maxillo-mandibular position [2].

The most sought after characteristic of interocclusal relation recording materials is their resistance to compression, after polymerization. The material should be rigid enough to resist distortion caused by the weight of dental moulds, of the articulator components or of other means used for model stabilization during the mounting procedure. Resistance to compression is very important since restoration errors occur due to the differences between the intra-oral relations and the articulator relations [2].

\section{Classification}

Dental materials may be classified as follows, according to their consistency and reversible or irreversible nature: irreversible rigid and semirigid materials: plaster, acrylic resins, zinc oxide pastes - eugenol, reversible rigid materials, Stents compounds, buccoplastic materials, gutta-percha, waxes, reversible elastic materials, reversible hydrocolloids, agar-agar, irreversible elastic materials - the most commonly used, irreversible hydrocolloids - alginates, synthesis elastomers - polysulphides, polyethers, and addition or condensation silicones [7].

\section{The classification suggested by leremia is the best known classification:}

Impression materials with short plasticity time and rigid consistency on their removal from the oral cavity (plaster, acrylic resins)

Impression materials with short plasticity time and semirigid consistency on their removal from the oral cavity (Stents and Kerr compounds, ZOE pastes)

Impression materials with short plasticity time and elastic consistency on their removal from the oral cavity (reversible hydrocolloids, irreversible hydrocolloids, polysulphide rubbers, silicone rubbers).

\section{Properties of the impression materials \\ Thermal properties}

Once inserted in the oral cavity under various forms, dental materials undergo changes caused by temperature. It is important to know in which manner these materials are heat conductors, and to know the dimensional variations accompanying the temperature changes. [4] When temperature changes, any body modifies its sizes. Heat dilation or expansion occurs when temperature increases, whereas heat contraction takes place when temperature decreases [4]. 
The mechanical properties of any material depend on the structure, shape, size, processing techniques, and physical and chemical influences under stress [4].

Depending on the behavior of the bodies after the stress has ceased, deformation may be elastic (the body resumes its initial shape) or plastic (the body does not resume its initial shape). The biggest concern is the connection which exists between the initial and the final shapes [4]. Elasticity is the property of any material of absorbing energy when it undergoes elastic deformation and of resuming its initial shape and sizes after the loads have been removed [4]. The phenomenon of decrease of the resistance of a material subjected to variable stresses, which causes the material to break prematurely due to per unit efforts lower than the material's resistance to tear is called material fatigue [4]. Generally, hardness is the property of a material to oppose the destruction of its surface layers under the action of another body [4].

When applying or removing the surface layer of certain materials, especially polymers, deformation may occur, the amplitude of which is time dependent. The elasticity module has different values depending on the time of its determination. The value determined after a short period of time (not immediately after insertion) is higher than the value determined after an infinite time, due to relaxation. This phenomenon is called visco-elasticity, due to the similitude of the behavior of such a solid with the behavior of a viscous fluid $[4,14,15]$.

Each impression material has different handling characteristics. It is very important to find a material which both the dental surgeon and the auxiliary personnel can work with.

Impression materials may be classified in two categories, depending on the humectation coefficient: hydrophilic and hydrophobic. Irreversible hydrocolloids (alginates), reversible hydrocolloids and polyethers are hydrophilic materials. Polysulphides, polyvinyl siloxanes with condensation reactions are hydrophobic materials. As far as impression materials are concerned, material viscosity varies depending on the type of materials. Low viscosity polysulphides and condensation silicones are the least viscous, whereas high viscosity polysulphides are at the other end of the viscosity range. Viscosity increases after the material mixing operation has begun [6].

Chemical properties - The absorption phenomenon consists of the imbibitions or retention in the mass of a liquid or solid environment of a substance in the gaseous, liquid or solid state. It is the consequence of a series of physical or chemical interactions [4].

Biological properties - Biocompatibility is a requirement that all dental materials inserted into the oral cavity should meet. Metals and non-noble alloys are the first ones that have proven harmful. Even today, many patients complain of local and general symptoms caused by incompatibilities, like intoxications, caused by dental materials or associations of such materials [4]. Impression materials are in contact with the oral mucosa only for a short time. Therefore, they are rather unlikely to trigger any allergic reactions. Nevertheless, these materials contain catalysts with allergenic potential; the allergy manifests itself by the occurrence of edemas [4]. Ideally, when making an impression, the dentist should use materials with the following properties: dimensional faithfulness and stability; easy handling; pleasant taste and smell; compatibility with oral fluids; non-irritant, non-allergenic; resistant to tear; compatible with the material that the model is made of.

These materials would benefit both to the dentist, due to the short setting time, and to the patient, for whom it would be easier to tolerate a material with a pleasant taste and smell. Last but not least, the elasticity coefficient of the material should be high, so that the latter be able to render all the details of the area in the mouth for which the impression was created, and easily resume its initial shape, i.e. the shape before its insertion into the mouth. Otherwise, difficulties may occur when removing the impression. Silicones, polyethers and polysulphides are the best ranking materials currently used in Romania, as they meet most of the criteria enumerated above.

Synthesis elastomers are available in four forms: PUTTY; HEAVY BODIED; REGULAR; LIGHT BODIED [5].

Silicone elastomers are classified in two groups: condensation and addition.

Condensation silicones - until the global acceptance of addition silicones, condensation silicones have been extremely popular in general dental practice due to their fastand clean handling. They are available in the four forms enumerated above, the putty-like and light bodied ones being the most commonly used. Light bodied silicone has the ability to render the details very clearly, but its resistance to tear is very low, making it very hard to handle [5].

Addition silicones - they are currently the most popular elastomers.

This material has rather low resistance to tear and is predisposed to tear if there are dimples and deep gum grooves on the impression surface. The impression should be removed carefully. Another drawback is the fact that currentadhesives are not too compatible with the material and hollows may be seen in the impressions. They are not always visible, but they may trigger edge adaptation problems or the prosthetic device may just not fit properly.

Addition silicones have poor humectation characteristics and they are also hydrophobic. This could mean lower faithfulness. Humectation agents were useful both in the laboratory and intraorally and they were the best solution to overcome this drawback. The biggest advantage of addition silicones is their excellent dimensional stability [5].

A clinically accepted prosthetic device should be in harmony with the existing stomatognathic system. The recording and transfer of accurate occlusal data are the most important for a successful restoration. Interocclusal relation recording is a complex procedure which depends on the dentist's experience, expertise and skillfulness, on the chosen technique and, last but not least, on the selected material and its properties [1]. Interocclusal relation recording materials have been thoroughly studied over time. The studies conducted are aimed at determining their faithfulness, dimensional precision and easiness of use in the positioning of the models employed to develop the prosthetic devices $[1,2,7,9,10]$. The choice of the interocclusal recording material is still very challenging for dentists, for which reason we found it necessary to study them, to emphasize the characteristics differentiating them and to determine which is the ideal material for these recordings $[13,16]$.

The goal of this study is to compare and assess the reliability and dimensional stability of seven interocclusal relation recording materials, in order to help clinicians get a clear image of their use in current practice.

\section{Experimental part \\ Material and method}

The interocclusal relation recording materials used for this study were seven silicones, six of which with addition reaction, five with special destination for interocclusal 

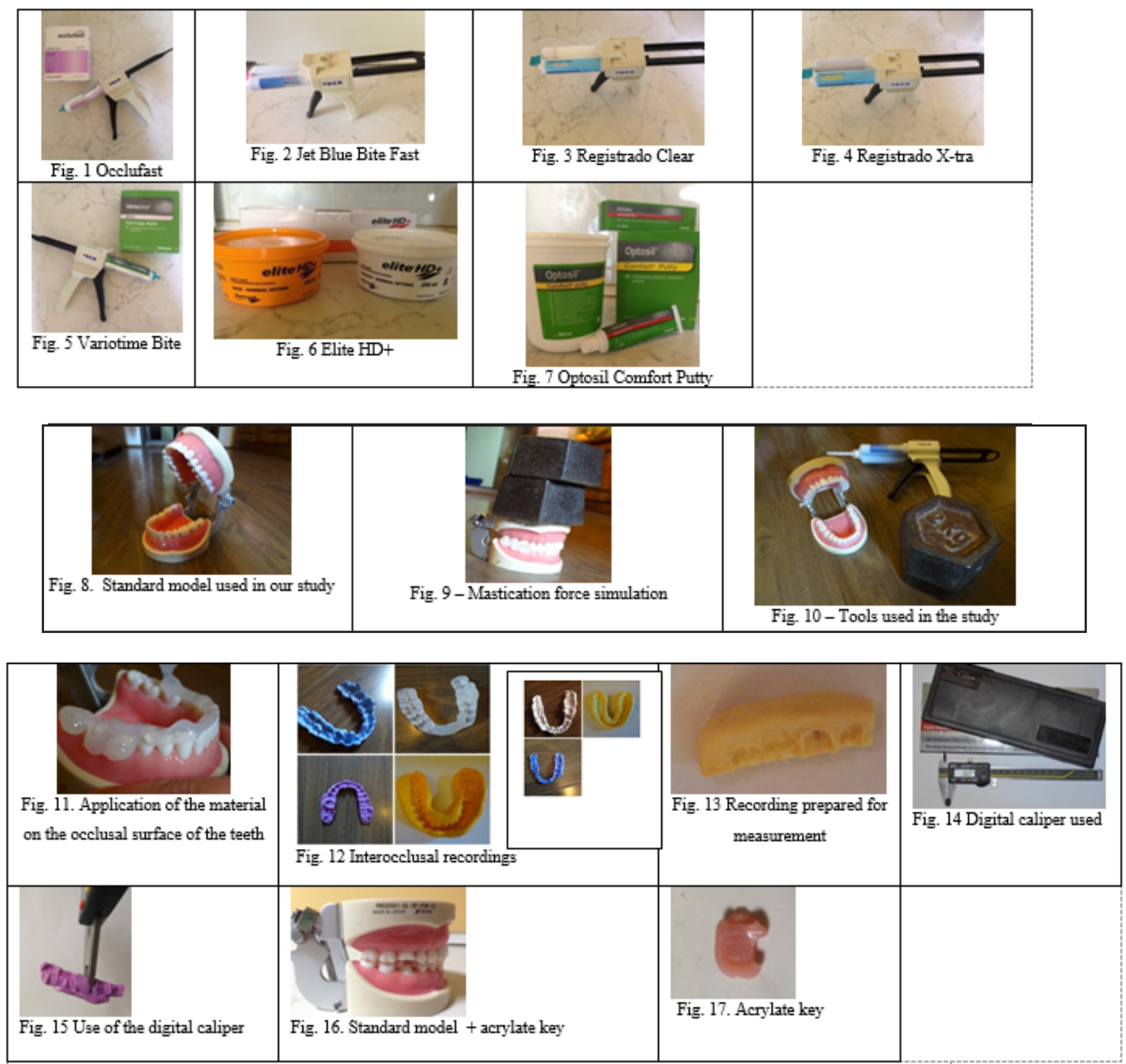

relation determination and a putty-like silicone normally used for dental arch impression - Elite HD (fig. 1-6) and one condensation silicone used for impressions (fig. 7). The reason for choosing the last two materials was the fact that some practitioners frequently use putty-like impression silicone to determine interocclusal relations.

A FRASACO model was used to make the recording, which served to the grinding of tooth 1.6 and of its opposite tooth, 4.6; their surfaces were plane prepared in order to facilitate measurements (fig. 8).

Considering that the mean force generated by oral cavity closing is about four kilograms ( $39.2 \mathrm{~N}$ ), during the setting time of the recording materials we used two weights of two Kg each, which had previously undergone metrological testing. (fig. 9, 10).

Specimen preparation technique - We applied, one by one, the interocclusal relation recording materials on the occlusal surface of the teeth on the lower arch of the standard model, we put the two arches into contact and we placed a $4 \mathrm{~kg}$ weight on the model, after which we waited for the setting time to elapse, in compliance with the manufacturer's recommendations concerning the keeping of the two arches into contact (fig. 11).

For each recording we performed a cross section on the oral surface of the ground teeth in order to remove any excess material that could interfere with the thickness measuring tool and thus generate errors (fig. 13).

We used a digital caliper with $\pm 0.01 \mathrm{~mm}$ accuracy to measure the dimensional variations of interocclusal relation recordings (fig. 14). We set an electronic caliper positioning reference point on the occlusal surface, in the mesial part of the prepared tooth in order to determine the dimensional variations of the recording material thickness; we performed three measurements for each determination and we used their arithmetical mean (fig. 15).

We performed measurements at differenttime intervals, namely: on the day of the impression, 24 hours, 72 hours and $120 \mathrm{~h}$ after the first recording. On the day of the impression, measurements were conducted every hour, until the dimensional stabilization of all the recording materials. The millimeter was the unit of measurement that we used. In order to have a standard reference, against which to measure the findings of the measurements of the materials used to determine interocclusal relations, we conducted an interocclusal recording in the ground teeth. It was obtained by means of an autopolymerizing acrylate key (DURACRYL), which was kept between the two arches until the setting process was completed (fig. 16,17).

The statistical analysis was done in Excel and by means of the GraphPad Instat 3 statistical software. We 


\begin{tabular}{|c|c|c|c|c|c|c|c|c|}
\hline & $\begin{array}{c}\text { Registrad } \\
\text { o X-tra }\end{array}$ & $\begin{array}{c}\text { Jet Blue } \\
\text { Bite }\end{array}$ & $\begin{array}{c}\text { Registrad } \\
\text { o Clear }\end{array}$ & Occlufast & Variotime & Elite HD & $\begin{array}{l}\text { Optosil } \\
\text { Comfort }\end{array}$ & \multirow{11}{*}{$\begin{array}{c}\text { Table } 1 \\
\text { INTEROCCLUSAL } \\
\text { RECORDING } \\
\text { THICKNESS }\end{array}$} \\
\hline T0 & 3.26 & 3.02 & 3.01 & 3.23 & 3.06 & 3.01 & 3.02 & \\
\hline lh & 3.32 & 3.07 & 3.04 & 3.27 & 3.18 & 3.07 & 3.21 & \\
\hline $2 \mathrm{~h}$ & 3.34 & 3.09 & 2.94 & 3.31 & 3.11 & 3.10 & 3.23 & \\
\hline $3 \mathrm{~h}$ & 3.33 & 3.06 & 2.99 & 3.23 & 3.12 & 3.10 & 3.23 & \\
\hline $4 \mathrm{~h}$ & 3.34 & 3.08 & 3.00 & 3.23 & 3.11 & 3.10 & 3.23 & \\
\hline $5 \mathrm{~h}$ & 3.34 & 3.08 & 3.00 & 3.23 & 3.11 & 3.10 & 3.23 & \\
\hline $24 \mathrm{~h}$ & 3.32 & 3.10 & 3.00 & 3.23 & 3.10 & 3.01 & 3.28 & \\
\hline $72 \mathrm{~h}$ & 3.28 & 3.15 & 3.00 & 3.23 & 3.12 & 3.01 & 3.32 & \\
\hline $120 \mathrm{~h}$ & 3.29 & 3.15 & 3.01 & 3.23 & 3.17 & 3.00 & 3.30 & \\
\hline $\mathrm{M}( \pm)$ & $\begin{array}{c}3.31 \\
( \pm 0.029)\end{array}$ & $\begin{array}{c}3.09 \\
( \pm 0.041)\end{array}$ & $\begin{array}{c}3.00 \\
( \pm 0.026)\end{array}$ & $\begin{array}{c}3.24 \\
( \pm 0.028)\end{array}$ & $\begin{array}{c}3.12 \\
( \pm 0.036)\end{array}$ & $\begin{array}{c}3.06 \\
( \pm 0.046)\end{array}$ & $\begin{array}{c}3.23 \\
( \pm 0.086)\end{array}$ & \\
\hline
\end{tabular}

\begin{tabular}{|c|c|c|c|}
\hline $\begin{array}{c}\text { Compared param- } \\
\text { eters }\end{array}$ & $\begin{array}{c}\text { Difference of } \\
\text { means }\end{array}$ & $\mathbf{q}$ & p value \\
\hline Registrado X-tra vs Jet Blue Bite & 0.2244 & 14.524 & $* * * \mathrm{P}<0.001$ \\
\hline Registrado X-tra vs Registrado Clear & 0.3144 & 20.348 & $* * * \mathrm{P}<0.001$ \\
\hline Registrado X-tra vs Occlufast & 0.07000 & 4.530 & ${ }^{*} \mathrm{P}<0.05$ \\
\hline Registrado X-tra vs Variotime & 0.1933 & 12.511 & $* * * \mathrm{P}<0.001$ \\
\hline Registrado X-tra vs Elite HD & 0.2578 & 16.681 & $* * * \mathrm{P}<0.001$ \\
\hline Registrado X-tra vs Optosil Comfort & 0.08556 & 5.536 & ${ }^{* *} \mathrm{P}<0.01$ \\
\hline Jet Blue Bite vs Registrado Clear & 0.09000 & 5.824 & ${ }^{* *} \mathrm{P}<0.01$ \\
\hline Jet Blue Bite vs Occlufast & -0.1544 & 9.994 & $* * * \mathrm{P}<0.001$ \\
\hline Jet Blue Bite vs Variotime & -0.03111 & 2.013 & ns $\mathrm{P}>0.05$ \\
\hline Jet Blue Bite vs Elite HD & 0.03333 & 2.157 & ns $\mathrm{P}>0.05$ \\
\hline Jet Blue Bite vs Optosil Comfort & -0.1389 & 8.988 & $* * * \mathrm{P}<0.001$ \\
\hline Registrado Clear vs Occlufast & -0.2444 & 15.818 & $* * * \mathrm{P}<0.001$ \\
\hline Registrado Clear vs Variotime & -0.1211 & 7.837 & $* * * \mathrm{P}<0.001$ \\
\hline Registrado Clear vs Elite HD & -0.05667 & 3.667 & ns $\mathrm{P}>0.05$ \\
\hline Registrado Clear vs Optosil Comfort & -0.2289 & 14.812 & $* * * \mathrm{P}<0.001$ \\
\hline Occlufast vs Variotime & 0.1233 & 7.981 & $* * * \mathrm{P}<0.001$ \\
\hline Occlufast vs Elite HD & 78 & 12.151 & $* * * \mathrm{P}<0.001$ \\
\hline Occlufast vs Optosil Comfort & 0.01556 & 1.007 & ns $\mathrm{P}>0.05$ \\
\hline Variotime vs Elite HD & 0.06444 & 4.170 & ns $\mathrm{P}>0.05$ \\
\hline Variotime vs Optosil Comfort & -0.1078 & 6.974 & $* * * \mathrm{P}<0.001$ \\
\hline Elite HD vs Optosil Comfort & -0.1722 & 11.145 & $* * * \mathrm{P}<0.001$ \\
\hline
\end{tabular}

Table 2

FINDINGS OF THE TURKEYKRAMER MULTIPLE COMPARISON TEST considered the mean $(M)$ and standard deviation $(S D / \pm)$, and set the statistical significance for $p<0.05$.

Findings - The interocclusal dimension measured at the level of the acrylate key was $3.00 \mathrm{~mm}$. The parameters determined by the measurements performed are shown in the following table:

In order to reveal the differences between the materials used we applied the ANOVA parametric test and got a statistically significant difference $(p<0.0001)$ between the measured parameters. The findings of the Turkey-Kramer multiple comparison test are shown in table 2.

The figures hereunder show comparisons of the dimensional variations between materials.

The table hereunder shows the comparative findings of the dimensional variation test conducted on the materials used to determine interocclusal relations and the dimension considered as standard dimension. 


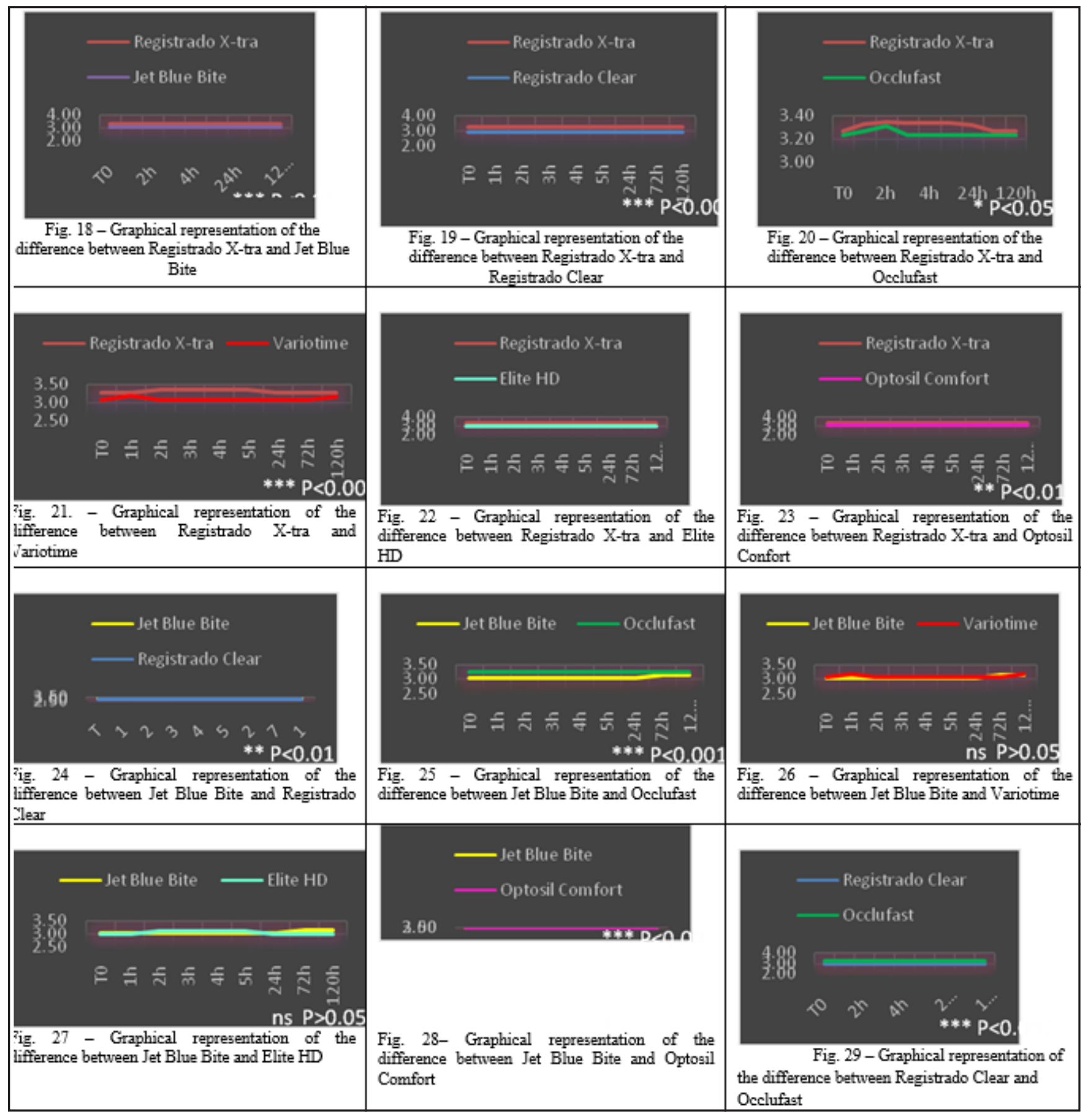

\section{Results and discussions}

According to the findings of the measurements shown in table 1, after the initial impression, at the moment T0, we had satisfactory results both for addition silicones, and for condensation silicones, Registrado X-tra being the only recording material with major deviation from the standard dimension ( $3 \mathrm{~mm}$ ).

As far as the Optosil condensation silicone is concerned, we noticed a significant increase in the thickness of the material starting with the first hour after impression. On the $5^{\text {th }}$ day, it reached considerable values, i.e. $0.3 \mathrm{~mm}$ higher than the standard value. The smallest differences from the standard value were noted in Registrado Clear and Elite HD+.

The Registrado Clear addition silicone exhibited no significant changes 4 hours after the moment T0 and reached a dimensional stability, i.e. a value equal to the one of the acrylate key.

We also had satisfactory results with the Elite HD+ silicone, which managed to become stable and get close to the standard dimension after $24 \mathrm{~h}$.
The Registrado X-tra material did not reach dimensional stability by the $5^{\text {th }}$ day, the difference from the standard value being relatively significant, i.e. $0.31 \mathrm{~mm}$.

On moment T0 we also achieved good results for the J et Blue Bite material, the difference against the standard value being about $0.02 \mathrm{~mm}$. On the next measurements, i.e. an hour after the first recording, we noted a continuous growth of the material, and reached a $0.15 \mathrm{~mm}$ difference on the $5^{\text {th }}$ day.

The Occlufast polyvinyl siloxane became stable $3 \mathrm{~h}$ after the initial recording, and on moment TO its values were rather high compared to the reference value. The measurements revealed a peak $2 \mathrm{~h}$ after the impression and became stable after 3 hours, the difference between the final dimension and the reference dimension being nonetheless significant, of approximately $0.23 \mathrm{~mm}$.

Rather good results were also noted for the Variotime material on the initial moment, the material revealing oscillatory dimension changes and reaching dimensional stability as late as day 5 . The difference is rather big from the standard acrylate key and was as high as $0.17 \mathrm{~mm}$. 


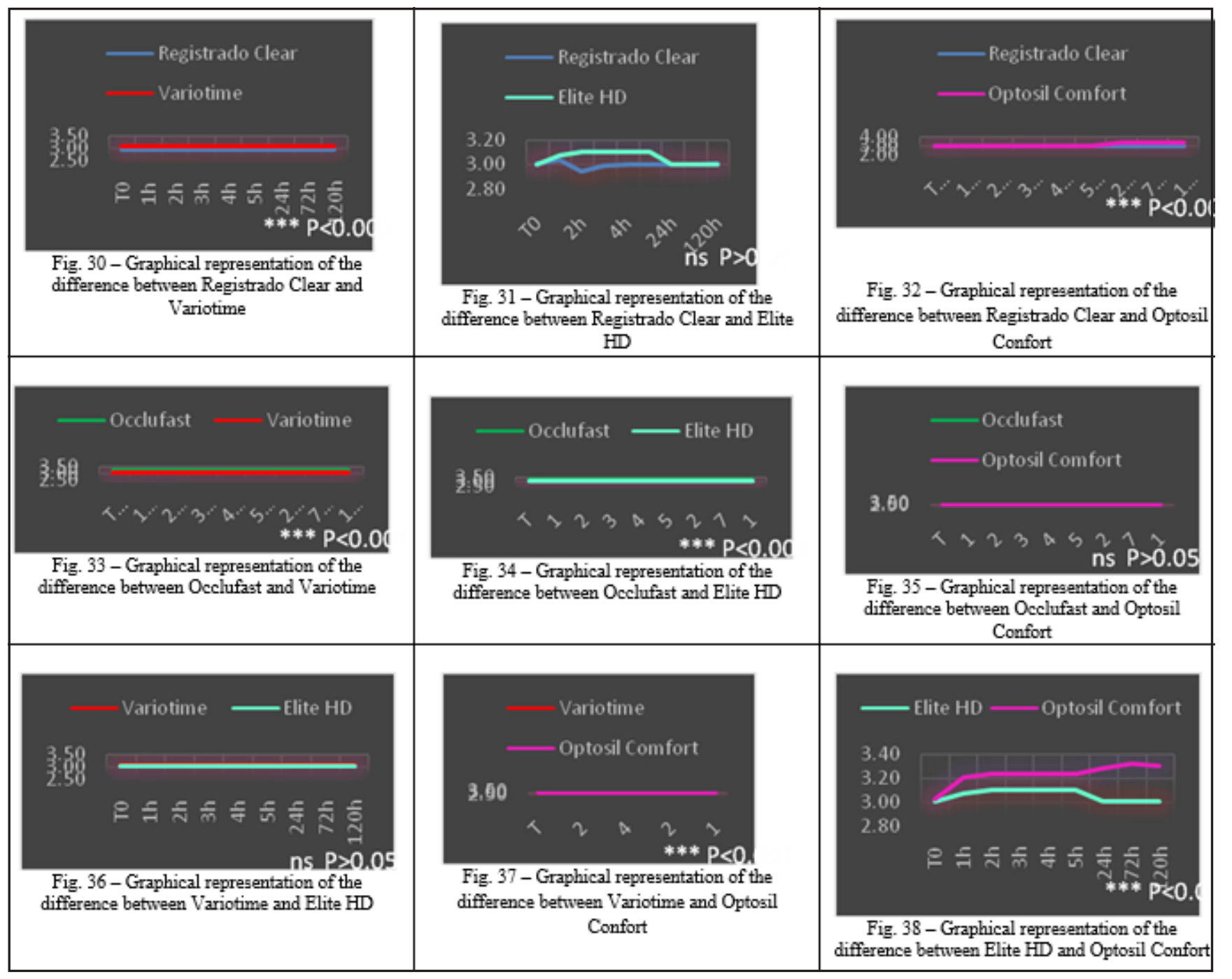

\begin{tabular}{|c|c|c|c|}
\hline Materials ujsed & Standard value & Value $\mathrm{p}$ & \\
\hline Registrado X-tra & \multirow{7}{*}{$3.00 \mathrm{~mm}$} & $* * * \mathrm{P}<0.0001$ & \multirow{7}{*}{$\begin{array}{l}\text { *statistical significance, } \\
\text { **high statistical } \\
\text { significance, ***extremely } \\
\text { high statistical significance, } \\
\text { ns - no statistical } \\
\text { significance }\end{array}$} \\
\hline Jet Blue Bite & & $* * * \mathrm{P}=0.0002$ & \\
\hline Registrado Clear & & ns $\mathrm{P}=0.9019$ & \\
\hline Occlufast & & $* * * \mathrm{P}<0.0001$ & \\
\hline Variotime & & $* * * \mathrm{P}<0.0001$ & \\
\hline Elite HD & & $* * \mathrm{P}=0.0073$ & \\
\hline Optosil Comfort & & $* * * \mathrm{P}<0.0001$ & \\
\hline
\end{tabular}

Table 3

FINDINGS OF THE COMPARISON OF THE RECORDINGS WITH THE STANDARDDIMENSION
In a similar study which tested the dimensional stability of polyvinyl siloxanes accompanied by changes in their weight we proved that all six materials included in the study exhibited insignificant dimensional changes, an assumption proven by our study. [] Prosthet Dent. 1994 Apr; 71(4): 400-3. Differential accuracy of elastomeric recording materials and associated weight change. Millstein PL1, Hsu CC.] A study conducted in 2014, which tested various interocclusal relation recording materials, proved that synthesis elastomers had the smallest dimensional variations compared to materials belonging to other classes $[2,11,12,16,17]$. Another study the findings of which are in agreement with the findings of our study was conducted by Chai J, Tan E, Pang IC. In this study, the authors tested different interocclusal relation recording materials (zinc oxide paste - eugenol, a polyether and seven addition silicones) and proved that, except for polyether, the other materials included in the study enjoyed dimensional stability. [ Int J Prosthodont. 1994 NovDec;7(6):538-42.A study of the surface hardness and dimensional stability of several intermaxillary registration
materials.Chai J, Tan E, Pang IC.] Similar findings with the ones in ourstudy were recorded by Preeti Agarwal Katyayan et al. in a study conducted in 2012, as well as by Rahul Nagrath, in a study carried out in 2014 [ 8, 9, 18-20]

In a study on the linear dimensional change accompanied by weight change, Michalakis KX et al. proved that polyethers exhibited the smallest changes over time, whereas addition silicones exhibited significant changes only after one hour and 24h. [] Prosthodont. 2004 Sep;13(3):150-9.An experimental study on particular physical properties of several interocclusal recording media. Part II: Linear dimensional change and accompanying weight change.Michalakis KX1, Pissiotis A, Anastasiadou V, Kapari D.]

\section{Conclusions}

Among the limitations of this study, we should mention the lack of high accuracy measuring devices, the fact that the study was conducted in vitro, without the influence of the oral cavity environment, the use of a $4 \mathrm{~kg}$ weight to simulate the closing force of the oral cavity and a single 
recording for each material. Despite these limitations, we may conclude as follows.

Rigid addition silicones have the lowest dimensional stability; putty silicones are frequently used to record interocclusal relations in fixed prosthetics, which is completely wrong since their size changes rapidly, i.e. their size increases, which impedes on the space between the prepared tooth and its opposite tooth, the result being a high restoration, which may determine premature contacts. Exceptfor Optosil, which exhibited a continuous increase, most materials may be used to mount models in the simulator after $24 \mathrm{~h}$.

Here is the decreasing stability ranking of special silicones used to determine interocclusal relations: Registrado Clear, Jet Blue Bite, Variotime, Occlufast, Registrado X-tra

Although it was not designed for this use, Elite HD may be an acceptable option for interocclusal recording.

The choice of the material is ultimately left to the dentist, but technicians should be familiar with these changes in order to avoid making poorly adapted prosthetic devices.

\section{References}

1.TEJ O, S. K., KUMAR, A. G., KATTIMANI, V. S., DESAI, P. D., NALLA, S., CHAITANYA, K. K., A comparative evaluation of dimensional stability of three types of interocclusal recording materials-an-in-vitro multicentre study; Head\&Face Medicine, 2012

2.CHANDU, G.S., et all, Evaluation and Comparison of Resistance to Compression of Various Interocclusal Recording Media. An In Vitro Study, 2014

3. CHECHERITA, L.E., FORNA, N.C., MACOVEI SURDU, A. et al.Influence of chemical therapeutical methods on manducatory muscles, Rev.Chim.(Bucharest), 64, no.11, 2013, p. 1312

4. BRATU, D., CIUSESCU, D., ROMINU, M.,et al.- Materiale Dentare in Cabinetul de Stomatologie, Ed. Helicon, Timi-oara, 1994, p. 7-88 5.BARTOK, F.F., FORNA, N.C., Peri-implantitis - a review of actual treatment methods. Romanian Journal of Oral Rehabilitation 2016; 8(3): 5-11.

6. BRATU, D., CIUSESCU, D., ROMINU, M.,et al.- Materiale Dentare. Bazele fiyico-chimice ale materialelor dentare, Ed. Helicon, Timisoara, 1994, p. 11-118

7.CHECHERITA, L., BELDIMAN, M.A.,STAMATIN, O., et al.Aspects on structure of materials used for different types of occlusal splints, Rev. Chim.(Bucharest), 64, no.8, 2013, p. 864

8. MARTU,S., CARUNTU,I.D., et all ,Healing process and laser therapy in the superficial periodontium: a histological study, Rom J Morphol Embryol, 2012, 53(1):3-6
9. ANCUTA, C., ANCUTA, E.,IORDACHE,C., et al, Immunohistochemical study of skeletal muscle in rheumatoid myositis, Romanian Journal of Morphology and embryology, 50(2), p:223-227, 2009

10. GAVRILA, L., BALAN, A., MURARIU, A., SANDU, A.V., SAVIN, C.,, In vitro Study Regarding the Effect of Various Commercial Remineralizing Products on Primary and Permanent Teeth Dentine Caries Lesions, Rev.Chim. (Bucharest), 67, no.11, 2016, p. 2228

11.J ACOBSEN, P., Restorative Dentistry-An integrated approach, 2008, p. 187-199

12.H.T., Fundamentals of Fixed Prosthodontics-Third Edition, 1997, p. 281-304

13. MURARIU, A., VASLUIANU,R., MATRICALA, L., STOICA, I., FORNA, N.C., In vitro evaluation of morphological integrity of dental enamel exposed to carbamide peroxide-based bleaching agent. Rev.Chim.(Bucharest), 67, no. 10, 2016, p. 2103

14. ANTOHE, M.E., DASCALU, C., SAVIN, C., FORNA, N.C., BALAN, A.,Study regarding the toxic effects of acrylic resins, Mat.Plast., 53, no. 4, 2016, p.767

15. PREETI, A.K., NATARAJAN, K., MANISH, K., Dimensional accuracy and detail reproduction of two hydrophilic vinyl polysiloxane impression materials tested under different conditions, Indian J Dent Res. 2011 Nov-Dec;22(6):881-2.

16.ANTOHE, M.E., AGOP FORNA, D.,DASCALU,C.G.,FORNA, N.C., The importance of observing the aesthetic requirements in partial edentulous rehabilitation - implications in medical-dental training, International Journal of education and information technologies Volume: 10 p. 199-203 Published: 2016

17. RAHUL, N., MANESH, L., VARUN, K., VARUN, G., A Comparative Study to Evaluate the Compression Resistance of Different Interocclusal Recording Materials: An In Vitro Study, J Indian Prosthodont Soc. 2014 Dec; 14(Suppl 1): p:76-85,2014

18. ANTOHE, M.E., FORNA AGOP,D., ANDRONACHE, M.,FEIER, R.,FORNA, N.C., Aspects of the therapy of partially extended edentation using modern methods - attachments as maintenance, support and stabilization, Romanian Journal of Oral Rehabilitation, 8(2), April - J une, 2016 , p.16-25

19.ANCUTA, C., POMIRLEANU, C.,IORDACHE,C., FATU, A.M., et al, Periodontal Disease and Lipid Profile in Systemic Sclerosis: an EUSTAR Cohort Experience, Rev.Chim.(Bucharest), 68, no. 4, 2017, p. 890 20. ANUP,G., AHILA,S.C.,VASANTHA KUMAR ,M., Evaluation of Dimensional Stability, Accuracy and Surface Hardness of Interocclusal Recording Materials at Various Time Intervals: An In Vitro Study, J Indian Prosthodont Soc. , Mar; 11(1): 26-31, 2011

Manuscript received: 15.03 .2017 